\title{
Predictors of Premature Clopidogrel Discontinuation within 30 days of Successful Coronary Artery Stenting
}

\author{
Çayan Çakir ${ }^{1}$, Haci Ates ${ }^{2}$, Baris Kiliçaslan³ ${ }^{3}$ Cem Nazli ${ }^{4}$ Oktay Ergene ${ }^{5}$ \\ 'Department of Cardiology, Van Training and Research Hospital, Van, ${ }^{4}$ Department of Cardiology, Izmir Ataturk Training and Research Hospital, ${ }^{3}$ Department of \\ Cardiology, Tepecik Training and Research Hospital, ${ }^{5}$ Department of Cardiology, Faculty of Medicine, Dokuz Eylul University, Izmir, ${ }^{2}$ Department of Cardiology, Private 7 \\ Mart Hospital, Kadirli/Osmaniye, Turkey
}

\section{Abstract}

Objective: We aimed to determine the prevalence, predictors, and mortality rate of premature clopidogrel discontinuation within 30 days of successful coronary stenting. Methods: All consecutive patients who underwent successful coronary stent implantation at our hospital between December 2006 and December 2007 were prospectively included in this study. Patients were interviewed by telephone 30 days after stent implantation. Premature clopidogrel discontinuation was defined as follows: patients who did not continue clopidogrel after discharge were defined as "never used" and patients who received clopidogrel for $<20$ days or interrupted therapy for at least 5 successive days within the first 30 days were defined as "partially used." Results: Follow-up data were available for 381 patients and 58 (15.2\%) patients reported premature clopidogrel discontinuation. No mortality and only $1(0.3 \%)$ stent thrombosis occurred in adherent patients, whereas there were $2(3.4 \%)$ mortalities and $6(10.3 \%)$ stent thrombosis in the patients who prematurely discontinued clopidogrel. Those who discontinued clopidogrel therapy were older $(P=0.02)$, more likely to be female $(P=0.02)$, single $(P=0.03)$, of lower economic $(P<0.05)$ and educational status $(P<0.01)$, more likely to have chronic disease $(P=0.04)$, less likely to have undergone previous stenting $(P=0.01)$, and were more likely to be receiving a larger number of drugs $(P<0.05)$. In multivariate analysis, low- or intermediate-economic status, no history of previous stent implantation, and total number of prescribed drugs using were factors independently associated with premature clopidogrel discontinuation. Conclusion: This study demonstrates several predictors of premature clopidogrel discontinuation. This data may help clinicians pay particular attention to these patients in an attempt to improve the outcomes of coronary stenting.

Keywords: Clopidogrel, mortality, stent

\section{INTRODUCTION}

Despite improvements in coronary stents and interventional techniques, stent thrombosis remains a major problem following percutaneous coronary interventions. Several clinical, anatomic, and procedural factors associated with stent thrombosis have been identified. ${ }^{[1,2]}$ Premature discontinuation of clopidogrel therapy has been reported to be associated with stent thrombosis, cardiac rehospitalization, cardiovascular death, and all-cause mortality. ${ }^{[3-5]}$ Although most of the factors associated with stent thrombosis are not modifiable, premature clopidogrel discontinuation may be reduced by preventative measures.

Several previous studies have reported predictors of premature clopidogrel discontinuation. ${ }^{[6-9]}$ However, recently, Khalili et al. reported that the models used to predict nonadherence perform

\begin{tabular}{|l|l|}
\hline \multicolumn{3}{|c|}{ Access this article online } \\
\hline Quick Response Code: & Website: \\
& http://www.ijcva.com \\
\cline { 2 - 2 } & \\
& \\
\end{tabular}

poorly. ${ }^{[10]}$ In this study, we aimed to determine the prevalence, predictors, and mortality rates of premature clopidogrel discontinuation following successful coronary stent implantation.

\section{Methods}

All consecutive patients who underwent successful coronary stent implantation at our hospital between December 2006 and December 2007 were prospectively included in this study. Patients who died because of reasons other than stent thrombosis during the same hospitalization, those who could not provide at least one telephone number for contact, and

Address for correspondence: Dr. Çayan Çakir, Van Training and Research Hospital, Van, Turkey. E-mail: cayancakir@hotmail.com

This is an open access journal, and articles are distributed under the terms of the Creative Commons Attribution-NonCommercial-ShareAlike 4.0 License, which allows others to remix, tweak, and build upon the work non-commercially, as long as appropriate credit is given and the new creations are licensed under the identical terms.

For reprints contact: reprints@medknow.com

How to cite this article: Çakir Ç, Ates H, Kiliçaslan B, Nazli C, Ergene O. Predictors of premature clopidogrel discontinuation within 30 days of successful coronary artery stenting. Int J Cardiovasc Acad 2018;4:1-5. 
those who refused to participate were excluded from this study. Patients were interviewed by telephone 30 days after stent implantation. Detailed data regarding the adherence to the prescribed medications and rehospitalizations were obtained. Definite and probable stent thrombosis was also determined. Premature clopidogrel discontinuation was defined as follows: patients who did not continue clopidogrel after discharge were defined as "never used" and patients who received clopidogrel for $<20$ days or interrupted therapy by at least 5 successive days within the first 30 days were defined as "partially used." The study complied with the principles of the Declaration of Helsinki, and the local Ethics Committee approved the study protocol.

\section{Statistical analysis}

Continuous variables were presented as mean \pm standard deviation or median ( $25 \%-75 \%$ percentiles), and categorical variables were expressed as number and percentage (\%). The continuous variables were compared across the groups using the Student's $t$-test or the Mann-Whitney U-test. The Kolmogorov-Smirnov test was used to identify normally distributed variables. The categorical variables were compared using the Chi-square or Fisher's exact tests. Forward and backward binary logistic regression analysis was performed to determine the independent predictors of premature clopidogrel discontinuation. The results were presented as odds ratios (OR) and 95\% confidence intervals (CI). Analysis of event-free survival was performed using the Kaplan-Meier method and the differences compared using the log-rank test. Event-free survival was defined as the time from enrollment in the study to the first event, which included death or stent thrombosis. All the data were analyzed with SPSS v14.0 for Windows (SPSS Inc., Chicago, IL, USA). A $P<0.05$ was considered to be statistically significant.

\section{RESULTS}

We prospectively enrolled 398 consecutive patients in this study. Among these, 13 (3.2\%) patients were lost to follow-up. A total of $6(1.5 \%)$ patients died within 30 days and data on clopidogrel maintenance could not be obtained from 4 of these. Therefore, 30-day follow-up data were available for 381 patients. Among the 381 patients, 278 (73\%) were men and $103(27 \%)$ were women. Mean age was $57.8 \pm 10.6$ years. Overall, $58(15.2 \%)$ patients reported premature clopidogrel discontinuation, while $323(84.8 \%)$ reported adherence to clopidogrel therapy [Figure 1]. No patient reported that they prematurley discontinued clopidogrel due to allergy, operation, or bleeding. The baseline characteristics of the patients are summarized in Table 1. Those who discontinued clopidogrel therapy were older $(P=0.02)$, more likely to be female $(P=0.02)$ and single $(P=0.03)$, had lower economic $(P<0.05)$ and educational statuses $(P<0.01)$, were more likely to have chronic disease $(P=0.04)$ and using larger number of drugs $(P<0.05)$, and less likely to have undergone previous stenting $(P=0.01)$. The mortality, stent thrombosis, and nonadherence to other

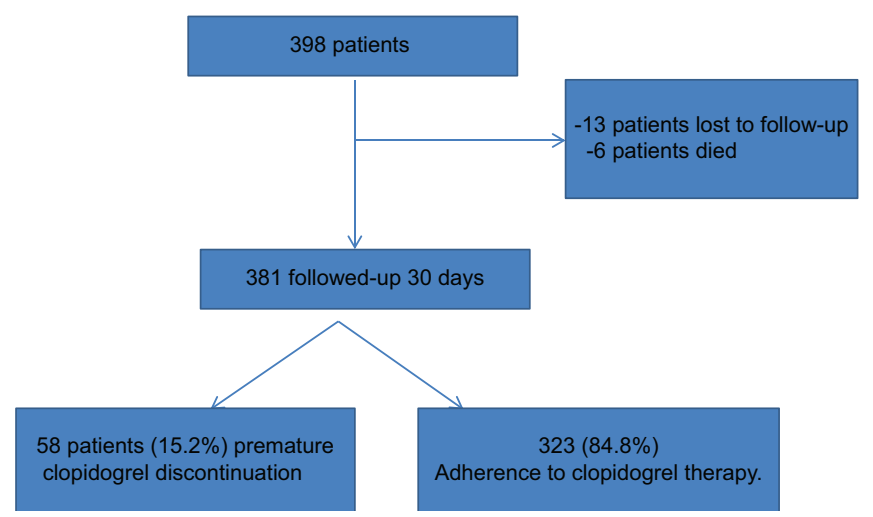

Figure 1: Flowchart of the study

cardiac drugs rates were significantly higher in patients who prematurely discontinued clopidogrel therapy within 30 days [Table 2]. Kaplan-Meier analysis showed that event-free survival within 30 days was higher in patients who adhered to clopidogrel therapy (log rank < 0.001) [Figure 2]. In multivariate analysis, low- and intermediate-economic status (OR: 7.299; 95\% CI: 2.642-20.167; $P<0.05$ and OR: 3.784; 95\% CI: 1.352-10.593; $P=0.0011$, respectively), no history of previous stent implantation (OR: 4.755; 95\% CI: $1.339-16.896 ; P=0.016$ ), and total number of prescribed drugs (OR: $1.940 ; 95 \%$ CI: $1.437-2.619 ; P<0.05$ ) were factors independently associated with premature clopidogrel discontinuation [Table 3]. On the other hand, age, sex, education status, marital status, living alone, and having chronic disease were not associated with premature clopidogrel discontinuation.

In the subgroup analysis, the patients who had never used clopidogrel were slightly younger than the adherent patients, but the difference was not statistically significant ( $53.5 \pm 10.3$ vs. $57.10 \pm 10.3, P=0.4$ ). Conversely, the patients who had partially used clopidogrel were significantly older than the adherent patients $(65.9 \pm 9.8$ vs. $57.10 \pm 10.3, P<0.005)$.

\section{Discussion}

In this study, we found that approximately 1 in 7 patients prematurely discontinued clopidogrel therapy within 30 days of coronary stent implantation. This prevalence is similar to previously reported rates. ${ }^{[6,11,12]}$ Except for one patient with stent thrombosis, all stent thrombosis and mortalities occurred among patients who prematurely discontinued clopidogrel therapy. A clear association between premature clopidogrel discontinuation and mortality/morbidity was apparent in concordance with previous reports. ${ }^{[4,13-15]} \mathrm{We}$ found that a lower economic status is the strongest predictor of premature clopidogrel discontinuation. The majority of the patients had health insurance. However, patients have to pay a partial contribution toward the costs of their prescribed medications and doctor's examination in Turkey. Even this minor contribution could have negative effects on economically disadvantaged patients' ability to start and 


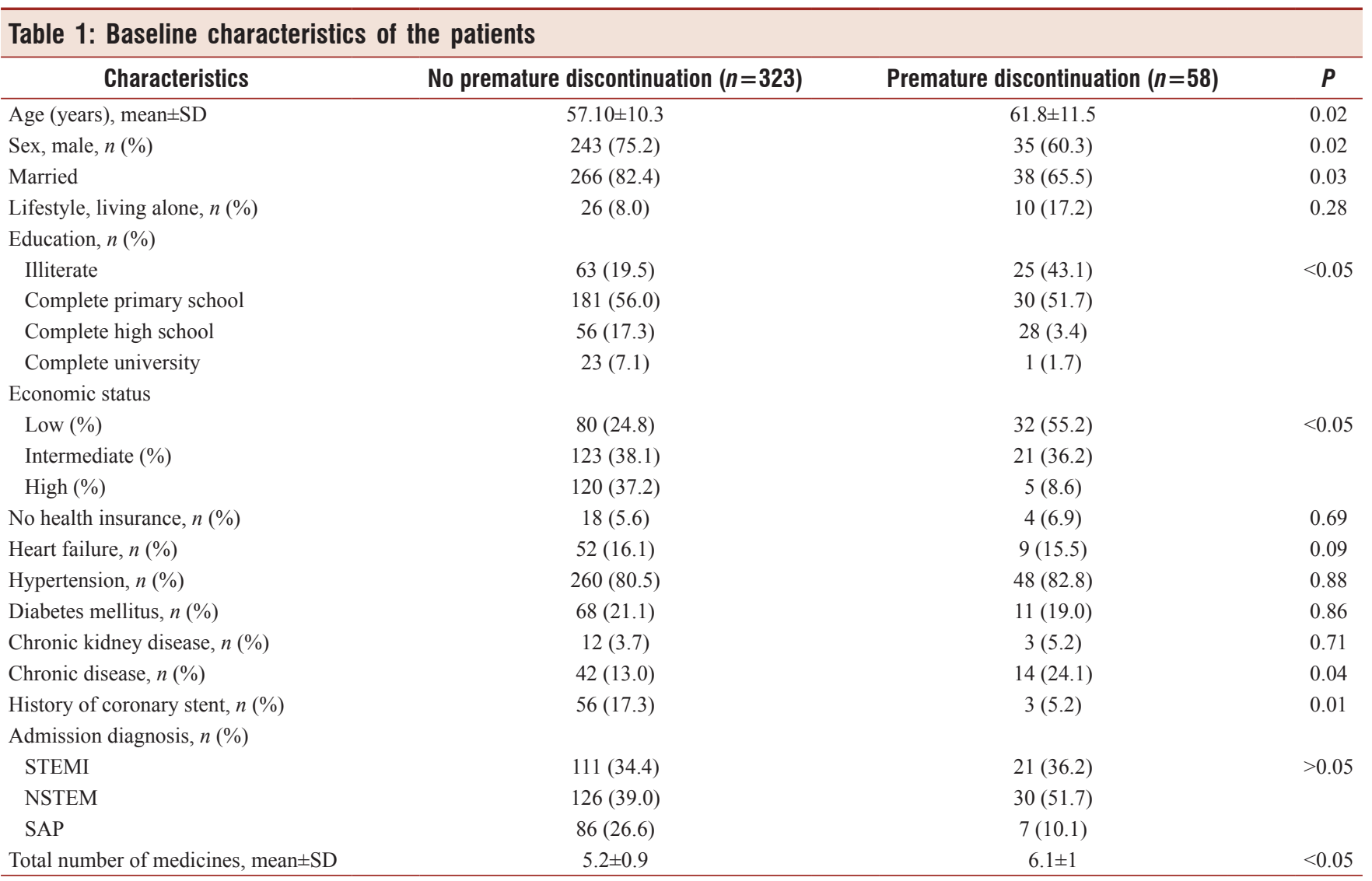

NSTEMI: Non-ST-segment elevation myocardial infarction, SAP: Stable angina pectoris, STEMI: ST-segment elevation myocardial infarction, SD: Standard deviation

Table 2: Stent thrombosis and mortality within 30 days and discontinuation of other cardiac medicines

\begin{tabular}{|c|c|c|c|}
\hline & No premature discontinuation $(n=323)$ & Premature discontinuation $(n=58)$ & $\boldsymbol{P}$ \\
\hline Stent thrombosis, $n(\%)$ (definite/probable) & $1(0.3)$ & $6(10.3)$ & $<0.05$ \\
\hline Mortality & 0 & $2(3.4)$ & 0.01 \\
\hline Discontinuation of other cardiac medicines, $n(\%)$ & $9(15.5)$ & $5(1.5)$ & $<0.05$ \\
\hline
\end{tabular}

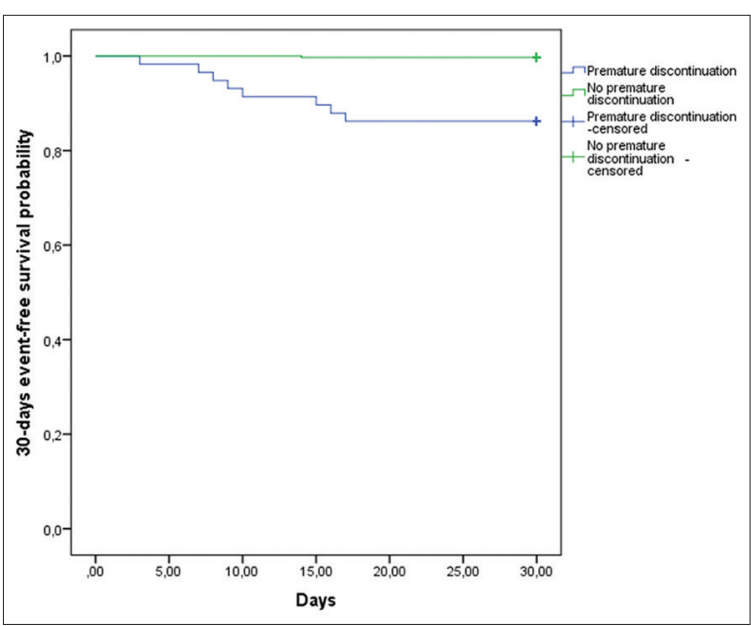

Figure 2: Kaplan-Meier curves for 30-days event-free survival for patients with clopidogrel therapy

maintain treatment without interruptions. Moreover, these patients may experience other unpredictable circumstances that may cause premature clopidogrel discontinuation. Similarly, Khalili et al. reported that although clopidogrel was provided at discharge and at nominal cost thereafter, a high rate of nonadherence was observed in a multiethnic, urban, and poor patient population. ${ }^{[10]}$

No history of previous coronary stenting was another strong predictor of premature clopidogrel discontinuation. This finding shows that patients who did not receive a prior coronary stent were not aware of the hazards of premature clopidogrel discontinuation. On the other hand, this finding also underscores our failure to properly educate patients on the significance of clopidogrel. A short but comprehensive educational session given to patients and their families or providing a printed educational pamphlet on clopidogrel and other medications before discharge may increase adherence to treatment. Using a large number of medications was another significant predictor of premature clopidogrel discontinuation. According to a report by the World Health Organization, approximately $50 \%$ of patients do not adhere to the prescribed 
Table 3: Predictors of premature clopidogrel discontinuation (backward logistic regression analysis)

\begin{tabular}{lccc}
\hline \multicolumn{1}{c}{ Parameter } & OR & $\mathbf{9 5 \%} \mathbf{C l}$ & $\boldsymbol{P}$ \\
\hline Low economic status & 7.299 & $2.642-20.167$ & $<0.05$ \\
Intermediate economic status & 3.784 & $1.352-10.593$ & 0.011 \\
No previous stent & 4.755 & $1.339-16.896$ & 0.016 \\
Total number of medicines & 1.940 & $1.437-2.619$ & $<0.05$ \\
Age & 1.029 & $0.998-1.61$ & 0.068 \\
\hline
\end{tabular}

OR: Odds ratio, CI: Confidence interval

long-term therapies for chronic conditions. ${ }^{[16]}$ In their multicenter study reflecting daily practice in Turkey, Kilic et al. had shown that $20.7 \%$ of patients with ischemic heart disease do not receive antiplatelet therapy. ${ }^{[17]}$ Poor medication adherence is multifactorial. Broadly, it may be classified as patient-related, physician-related, and health-care system/ team building-related factors. ${ }^{[18-20]}$ There are still several efforts that can be made to improve patient health literacy, patientphysician communication, and health-care system-related factors. ${ }^{[21]}$ In a review by Rashid et al., the dominant impact of clinicians on patients' medication adherence was described. The authors claimed that clinicians often unintentionally influence patients' thoughts through their language and lack of accessibility. ${ }^{[2]}$

In our study, we did not find the patients' education status to be an independent predictor of clopidogrel discontinuation. This result might be due to confounding effects of poor patientphysician communication and health-care system-related problems. Spertus et al. found that not completing high school was the only predictor of premature discontinuation of thienopyridine therapy. ${ }^{[5]}$ Age was also not an independent predictor of clopidogrel discontinuation in our study. In the subgroup analysis, while the mean age of patients who had never used clopidogrel after discharge was younger than the adherent patients, the difference was not statistically significant. Younger patients may be in denial about their illness, have a negative attitude toward taking medication, and/ or may believe that they have been cured by the interventions.

\section{Study limitations}

We conducted a single-center study with a relatively few number of patients. Second, we obtained data by a telephone call and by patient's self-reporting on their adherence. The self-reported adherence data might be unreliable. An additional concern is that $3.2 \%$ of patients were lost to follow-up at 30 days and we were unable to obtain data on their adherence or other possible adverse events. Therefore, we may have underestimated the true rates of premature clopidogrel discontinuation. Although our study was not conducted recently, we believe that it still provides relevant and current information.

\section{Conclusion}

Improving patients' adherence to their medications is a significant task and an opportunity to decrease stent thrombosis and related morbidity and mortality. Further, studies with more patients are necessary to determine the predictors of premature clopidogrel discontinuation.

\section{Financial support and sponsorship \\ Nil.}

\section{Conflicts of interest}

There are no conflicts of interest.

\section{ReFERENCES}

1. Moussa I, Di Mario C, Reimers B, Akiyama T, Tobis J, Colombo A, et al. Subacute stent thrombosis in the era of intravascular ultrasound-guided coronary stenting without anticoagulation: Frequency, predictors and clinical outcome. J Am Coll Cardiol 1997;29:6-12.

2. Sudhir K, Hermiller JB, Ferguson JM, Simonton CA. Risk factors for coronary drug-eluting stent thrombosis: Influence of procedural, patient, lesion, and stent related factors and dual antiplatelet therapy. ISRN Cardiol 2013;2013:748736.

3. Iakovou I, Schmidt T, Bonizzoni E, Ge L, Sangiorgi GM, Stankovic G, et al. Incidence, predictors, and outcome of thrombosis after successful implantation of drug-eluting stents. JAMA 2005;293:2126-30.

4. Cutlip DE, Baim DS, Ho KK, Popma JJ, Lansky AJ, Cohen DJ, et al. Stent thrombosis in the modern era: A pooled analysis of multicenter coronary stent clinical trials. Circulation 2001;103:1967-71.

5. Vigen R, Maddox TM, O’Donnell CI, Grunwald GK, Bhatt DL, Tsai TT, et al. Hospital variation in premature clopidogrel discontinuation after drug-eluting stent placement in the veterans affairs (VA) healthcare system. J Am Heart Assoc 2016;5. pii: e001376.

6. Spertus JA, Kettelkamp R, Vance C, Decker C, Jones PG, Rumsfeld JS, et al. Prevalence, predictors, and outcomes of premature discontinuation of thienopyridine therapy after drug-eluting stent placement: Results from the PREMIER registry. Circulation 2006;113:2803-9.

7. Ferreira-González I, Marsal JR, Ribera A, Permanyer-Miralda G, García-Del Blanco B, Martí G, et al. Background, incidence, and predictors of antiplatelet therapy discontinuation during the first year after drug-eluting stent implantation. Circulation 2010;122:1017-25.

8. Muntner P, Mann DM, Woodward M, Choi JW, Stoler RC, Shimbo D, et al. Predictors of low clopidogrel adherence following percutaneous coronary intervention. Am J Cardiol 2011;108:822-7.

9. Rossini R, Capodanno D, Lettieri C, Musumeci G, Nijaradze T, Romano M, et al. Prevalence, predictors, and long-term prognosis of premature discontinuation of oral antiplatelet therapy after drug eluting stent implantation. Am J Cardiol 2011;107:186-94.

10. Khalili H, Singh R, Wood M, Edwards A, Cooper M, Ayers C, et al. Premature clopidogrel discontinuation after drug-eluting stent placement in a large urban safety-net hospital. Am J Cardiol 2016;117:522-5.

11. Sheehy O, LeLorier J, Rinfret S. Restrictive access to clopidogrel and mortality following coronary stent implantation. CMAJ 2008; 178:413-20.

12. Blich M, Shwiri TZ, Petcherski S, Osherov AB, Hammerman H. Clopidogrel therapy discontinuation following drug eluting stent implantation in real world practice in Israel. Cardiol Res 2012;3:67-72.

13. Eisenstein EL, Anstrom KJ, Kong DF, Shaw LK, Tuttle RH, Mark DB, et al. Clopidogrel use and long-term clinical outcomes after drug-eluting stent implantation. JAMA 2007;297:159-68.

14. Loh JP, Torguson R, Pendyala LK, Omar A, Chen F, Satler LF, et al. Impact of early versus late clopidogrel discontinuation on stent thrombosis following percutaneous coronary intervention with first- and second-generation drug-eluting stents. Am J Cardiol 2014;113:1968-76.

15. Zwart B, Godschalk TC, Kelder JC, Ten Berg JM. High risk of stent thrombosis in the first 6 months after coronary stenting: Do not discontinue clopidogrel early after ACS. J Interv Cardiol 2017;30:421-6.

16. Brown MT, Bussell JK. Medication adherence: WHO cares? Mayo Clin 
Proc 2011;86:304-14.

17. Kilic S, Sümerkan MÇ, Emren V, Bekar L, Çersit S, Tunç E, et al. Secondary prevention of coronary heart disease in elderly population of Turkey: A subgroup analysis of ELDERTURK study. Cardiol J 2017. doi: 10.5603/CJ.a2017.0113.

18. De Geest S, Sabaté E. Adherence to long-term therapies: Evidence for action. Eur J Cardiovasc Nurs 2003;2:323.

19. Jimmy B, Jose J. Patient medication adherence: Measures in daily practice. Oman Med J 2011;26:155-9.

20. Stevenson FA, Cox K, Britten N, Dundar Y. A systematic review of the research on communication between patients and health care professionals about medicines: The consequences for concordance. Health Expect 2004;7:235-45.

21. Kubica A, Obońska K, Fabiszak Ts, Kubica J. Adherence to antiplatelet treatment with $\mathrm{P} 2 \mathrm{Y} 12$ receptor inhibitors. Is there anything we can do to improve it? A systematic review of randomized trials. Curr Med Res Opin 2016;32:1441-51.

22. Rashid MA, Edwards D, Walter FM, Mant J. Medication taking in coronary artery disease: A systematic review and qualitative synthesis. Ann Fam Med 2014;12:224-32. 